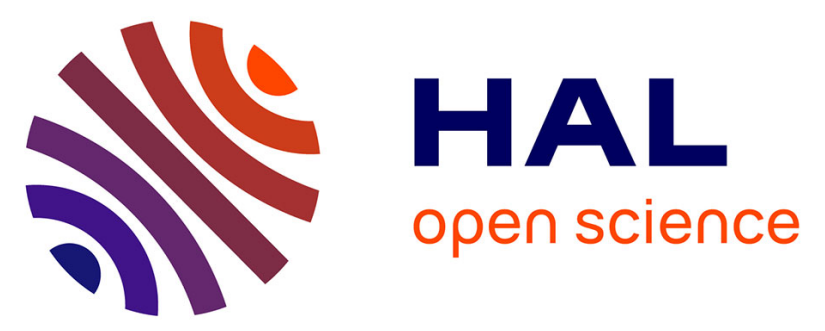

\title{
Dam-break flows over mobile beds: experiments and benchmark tests for numerical models
}

Sandra Soares-Frazao, Ricardo Canelas, Zhixian Cao, Luis Cea, Hanif

Chaudhry, Andres Die Moran, Kamal El Kadi, Rui Ferreira, Ignacio

Cadorniga, Noemi Gonzalez-Ramirez, et al.

\section{To cite this version:}

Sandra Soares-Frazao, Ricardo Canelas, Zhixian Cao, Luis Cea, Hanif Chaudhry, et al.. Dam-break flows over mobile beds: experiments and benchmark tests for numerical models. Journal of Hydraulic Research, 2012, 50 (4), pp.364-375. 10.1080/00221686.2012.689682 . hal-00798131

\section{HAL Id: hal-00798131 \\ https://hal-enpc.archives-ouvertes.fr/hal-00798131}

Submitted on 15 May 2020

HAL is a multi-disciplinary open access archive for the deposit and dissemination of scientific research documents, whether they are published or not. The documents may come from teaching and research institutions in France or abroad, or from public or private research centers.
L'archive ouverte pluridisciplinaire HAL, est destinée au dépôt et à la diffusion de documents scientifiques de niveau recherche, publiés ou non, émanant des établissements d'enseignement et de recherche français ou étrangers, des laboratoires publics ou privés. 


\title{
Dam-break flows over mobile beds: Experiments and benchmark tests for numerical models
}

By:

IAHR Working group for Dam-break flows over mobile beds

A detailed list of authors is provided at the end of the paper

\section{Corresponding author:}

\section{Sandra Soares-Frazão}

Fonds de la Recherche Scientifique (FNRS) and Université catholique de Louvain, Institute of Mechanics, Materials and Civil Engineering (iMMC), Civil and Environmental Engineering, Place du Levant 1, B-1348 Louvain-la-Neuve, Belgium.

Tel: +32-10-47 2120

Fax: +32-10-47 2179

e- mail: sandra.soares-frazao@uclouvain.be

\begin{abstract}
This paper presents the results of a benchmark test that was launched within the frame of the NSF-PIRE project "Modelling of Flood Hazards and Geomorphic Impacts of Levee Breach and Dam Failure". Experiments of two-dimensional dam-break flows over a sand bed were conducted at the Université catholique de Louvain, Belgium. The water level evolution at 8 gauging points was measured as well as the final bed topography. Intense scouring occurred close to the failed dam, while significant deposition areas were observed further downstream. From these experiments, a benchmark was proposed to the scientific community, consisting of blind simulations of the tests, i.e. without any prior knowledge of the measurements. Twelve different teams of modellers from eight different countries participated. We briefly present the range of numerical models that were used in the benchmark test and comment on some results obtained, in view of evaluating their capabilities and identify the challenges that may open pathways for further research.
\end{abstract}

Keywords: benchmark test, dam-break, experiment, numerical simulations, sediment

\section{Introduction}

Fast transient flows induced by the breaking of a dam or any control structure can seriously affect the neighbouring population, causing loss of lives and important material damage. In case of erodible bed, intense sediment transport occurs that can in some cases reach a similar order of magnitude as the amount of transported water (Capart, 2000). The associated morphological changes can be such that the entire valley might be reshaped, as occurred for example during the 1996 dam-break flood along the Ha!Ha! River in Quebec (Capart et al. 2007, Brooks and Lawrence 1999).

One of the consequences of the global climate change is an increased risk of failure for many structures that were designed for discharges and precipitations that are often no more adapted to the present-day conditions. Many research initiatives were devoted in the last years to related questions (e.g. the European project FLOODsite). Numerical models are widely used to assess the consequences of a potential failure. However, most of the studies are conducted assuming pure hydrodynamic flows, i.e. neglecting morphological effects (e.g. Hervouet and 
Petitjean 1999, Valiani et al. 2002, Nguyen et al. 2006, Roger et al. 2009). In this framework, the shallow-water equations appear as a well-established choice and most of the existing models developed to solve these equations are able to produce valuable results that can be used for flood prediction.

Intense sediment transport increases the level of uncertainty of simulation results. While it is generally agreed that an equation stating the conservation of the sediment mass should be added to the hydrodynamic equations, many open questions still exist regarding the inertia of moving sediment, the closure models for the transport rate, or the necessary simplifications to represent the complex reality of actual sediment-fluid interactions in a mathematical model.

To test and validate the numerous modelling options for fast-transient flows involving sediment transport, both laboratory and field data are needed. The latter data sets are scarce (yet see e.g. Capart et al. 2007) and often affected by uncertainties. Possible sources of uncertainty are related to the initial conditions, the discharge, the estimation of the maximum water level or the difficulty to obtain roughness coefficients and sediment characteristics. Therefore, laboratory data are of paramount importance for the validation of models. At the laboratory scale, it is possible to focus on a limited set of parameters, to accurately control the test conditions, and to repeat the experiment to enhance the dataset.

The present paper aims at providing test cases to validate numerical models for the simulation of dam-break flows over a mobile bed. The test cases consist of dam-break flows issuing from a 1-m breach flowing into a $3.6 \mathrm{~m}$ wide flume over a mobile bed made of uniform coarse sand. The test cases were proposed to the scientific community as a blind benchmark, i.e. as a modelling exercise without any prior knowledge of the measurements. Only the initial conditions were provided to the modellers. Twelve different teams of modellers from eight countries participated. Their results were compared to the experimental measurements during a workshop held in November 2010 in Louvain-la-Neuve, Belgium, within the frame of the NSF-PIRE project (grant $n^{\circ}$ OISE 0730246) entitled "Modelling of Flood Hazards and Geomorphic Impacts of Levee Breach and Dam Failure" and under the auspices of the IAHR Fluvial Hydraulics Committee. Detailed information about the benchmark session can be found at http://www.uclouvain.be/373040.html. The concerted analysis of these numerical results obtained without any model calibration is valuable in view of estimating the capabilities of current simulation tools for dam-break flows over mobile beds.

This paper presents the two test cases that were proposed as benchmark tests and the available experimental data. Then, some significant aspects of the comparison between numerical models and experimental data are illustrated, based on the simulation results of the benchmark session. Finally, conclusions are drawn about the modelling options, the capabilities of current numerical models and the need for further research to improve such models.

\section{Experiments}

\subsection{Experimental Set-up}

The experiments were conducted in the Hydraulics Unit of the LEMSC (Mechanical and Civil Engineering Laboratory, Université catholique de Louvain, Belgium). The flume (Figure 1) is $3.6 \mathrm{~m}$ wide and about $36 \mathrm{~m}$ long, from which the useful length in the present case is about $27 \mathrm{~m}$. The breached dam is represented by two impervious blocks and a 1-m wide gate located between the blocks. The origin of the axes is taken at the centre of the gate.

A $85 \mathrm{~mm}$ thick sand layer was laid onto the rigid bed of the flume. As illustrated in Figure 1, this sand layer extended over $9 \mathrm{~m}$ downstream of the gate and over about $1.5 \mathrm{~m}$ upstream of the gate. The sand was set in place without any compaction, and levelled by shifting a rigid 
beam. Downstream, the sand layer was held in place by a rigid sill whose height was equal to the initial layer thickness. The bed material consisted of uniform coarse sand (Figure 2) with the following characteristics: $d_{50}=1.61 \mathrm{~mm}$, specific gravity $\rho_{s} / \rho_{w}=2.63$ and initial porosity $\varepsilon_{0}=0.42$, the latter evaluated from sampling after deposition. A picture of the flume with the initial sand layer, before filling the reservoir with water, is provided in Figure 3.

A roughness Manning coefficient for the sand was measured under uniform flow conditions as $n=0.0165$; while it was observed from previous experiment that a value of $n=0.010$ can be adopted for the fixed bed.

The physical boundary conditions in the experiment consist of a closed wall at the upstream end of the flume and of a sediment trapping disposal at the downstream end. This downstream disposal is illustrated in Figure 4: it consists of a primary weir diverting the flow towards the sides of the channel with the aim of slowing the water down sufficiently for the sediment to deposit. The system was designed in such a way that all the sediments deposit in front of the primary weir. Should some grains travel further, they can still deposit in the side areas of the flume. The influence of this downstream boundary condition on the test results will be discussed in a further section.

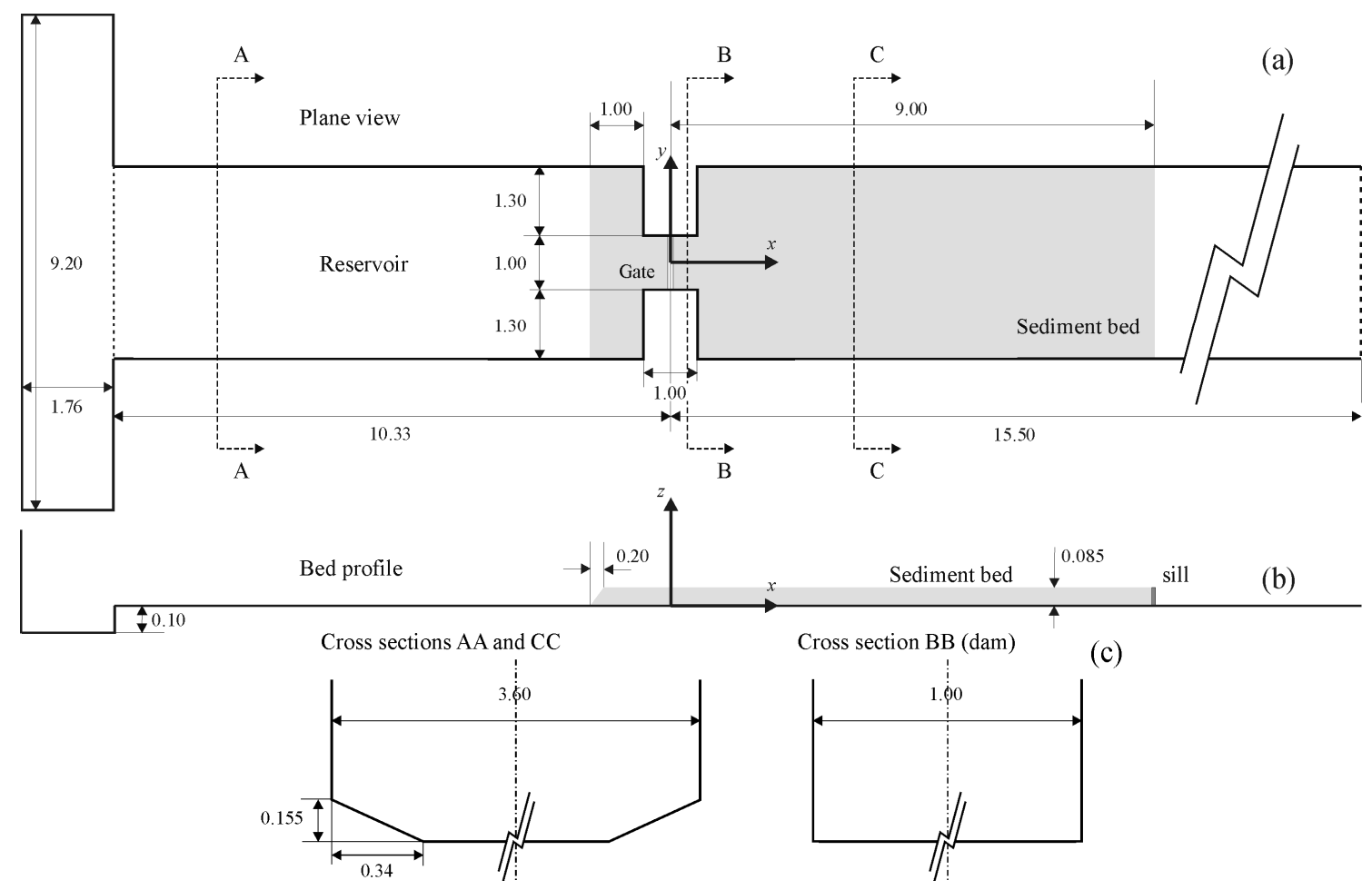

Figure 1. Flume dimensions (in meters): (a) plane view, (b) elevation, (c) cross sections 


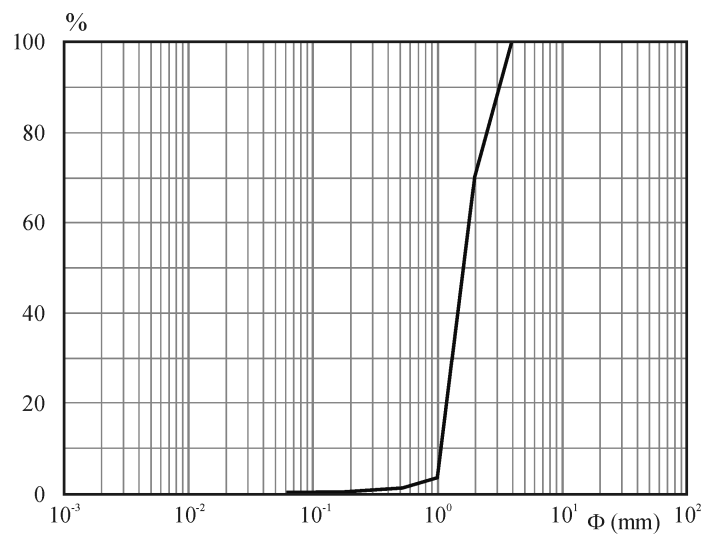

Figure 2. Bed material sieve curve

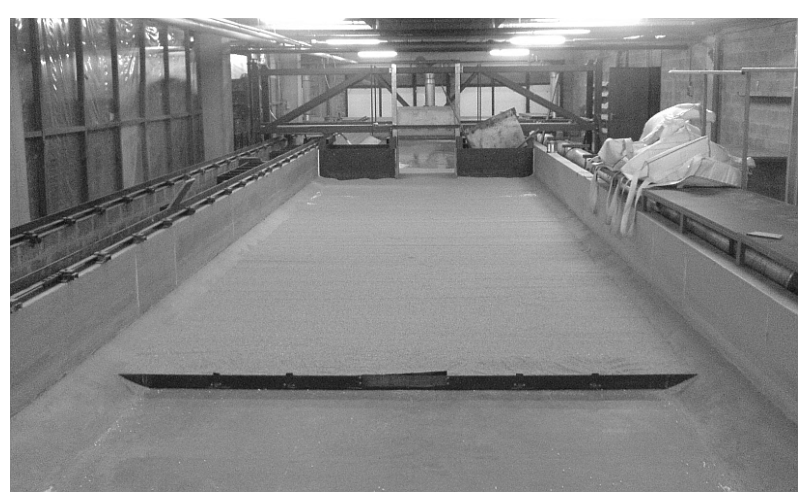

Figure 3. General view of the flume with the initial sand layer (view from downstream)

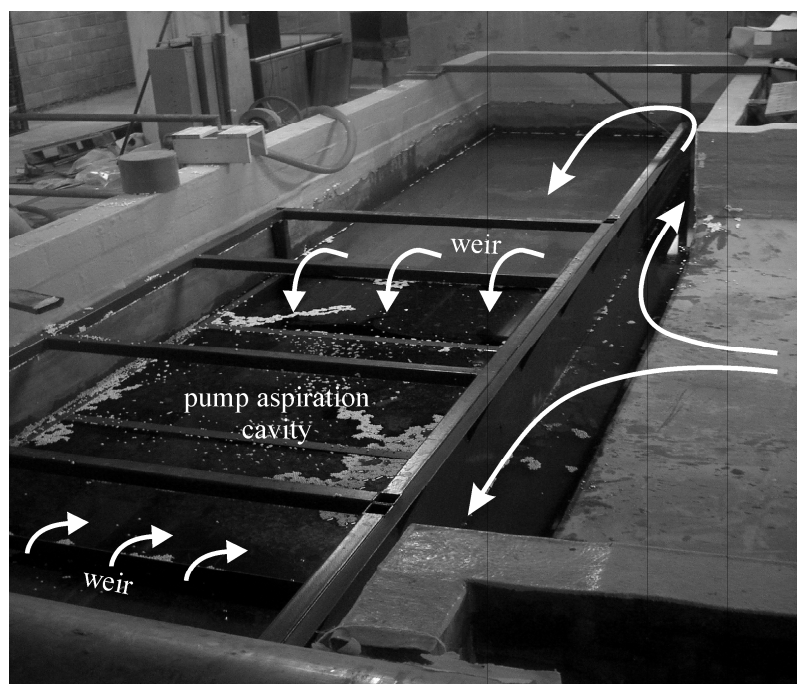

Figure 4. Downstream end of the flume

\subsection{Test conditions}

The experiments consisted in filling up the upstream reservoir with water, adjusting if necessary the water level downstream of the gate, then triggering a dam-break wave by rapidly pulling up the gate. Two different cases were considered, as summarized in Table 1. The initial water level in the upstream reservoir is denoted by $z_{0}$, while the initial water levels 
in the downstream part (Figure 1) are denoted $z_{1}$ in the sand-covered area $(0 \mathrm{~m}<\mathrm{x}<9 \mathrm{~m})$ and $z_{2}$ downstream of it $(\mathrm{x}>9 \mathrm{~m})$. Water levels are measured with reference to the fixed bed $(z=0 \mathrm{~m})$. In both cases, the initial sand layer of thickness $h_{s}=0.085 \mathrm{~m}$ was saturated before the experiment. For Case 1 where the initial level $z_{1}=0.085 \mathrm{~m}$ and $z_{2}=0 \mathrm{~m}$, the bed downstream of the sill was initially dry.

Table 1. Test conditions

\begin{tabular}{ccccc}
\hline & $z_{0}(\mathrm{~m})$ & $z_{1}(\mathrm{~m})$ & $z_{2}(\mathrm{~m})$ & $h_{s}(\mathrm{~m})$ \\
\hline Case 1 & 0.470 & 0.085 & 0.000 & 0.085 \\
Case 2 & 0.510 & 0.150 & 0.150 & 0.085 \\
\hline
\end{tabular}

To simulate the dam-break, the gate located at about $12 \mathrm{~m}$ from the upstream end of the flume was pulled up rapidly to reproduce an instantaneous dam break. The gate is pulled-up by a mechanical counterweight system, that is much more rapid that a pneumatic jacket for that scale of experiment. The opening time was measured in previous studies (Soares-Frazão and Zech, 2007) from digital images obtained at a high frequency. This opening time is defined as the time when the gate does not touch the water anymore and was found to be $0.23 \mathrm{~s}$. This value corresponds to an instantaneous dam-break (Vischer and Hager, 1998) for both initial conditions.

The experiment was considered to last $20 \mathrm{~s}$. After this time, the gate was closed and the flow was stopped. It was indeed observed that the morphological evolution was comparatively small after that instant.

\section{Available measurements}

\subsection{Water level}

During the experiments, the water level evolution in time was measured by means of 8 Baumer $^{\mathrm{TM}}$ ultrasonic probes (acquisition rate $12.5 \mathrm{~Hz}$ ). The location of the gauges for the two cases is indicated in Figure 5 and the exact positions are given in Table 2.

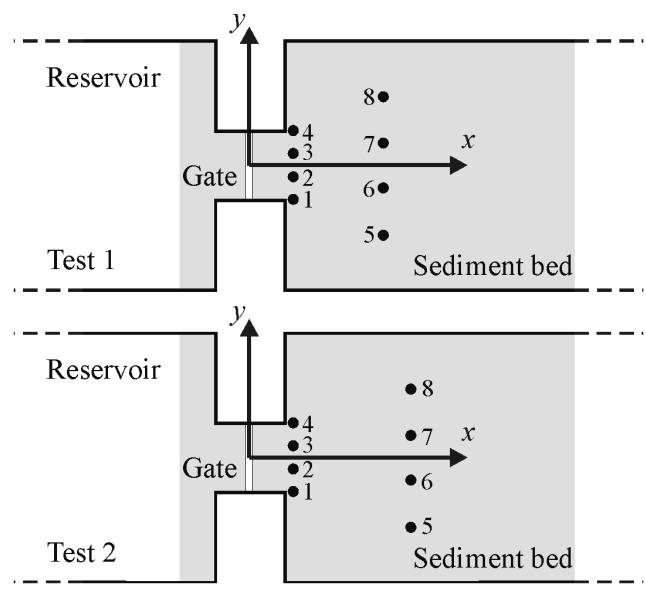

Figure 5. Gauge locations 
Table 2. Gauges locations for Case 1 and Case 2

Case 1

\begin{tabular}{ccccc}
\hline Gauge $^{\circ}$ & $x(\mathrm{~m})$ & $y(\mathrm{~m})$ & $x(\mathrm{~m})$ & $y(\mathrm{~m})$ \\
\hline US1 & 0.640 & -0.500 & 0.640 & -0.500 \\
US2 & 0.640 & -0.165 & 0.640 & -0.165 \\
US3 & 0.640 & 0.165 & 0.640 & 0.165 \\
US4 & 0.640 & 0.500 & 0.640 & 0.500 \\
US5 & 1.940 & -0.990 & 2.340 & -0.990 \\
US6 & 1.940 & -0.330 & 2.340 & -0.330 \\
US7 & 1.940 & 0.330 & 2.340 & 0.330 \\
US8 & 1.940 & 0.990 & 2.340 & 0.990 \\
\hline
\end{tabular}

Repeatability was checked by comparing the measured water level from different experiments performed in the same conditions. It can be observed from Figure 6 (Case 1) that a satisfactory level of repeatability could be achieved, given the experimental conditions involving intense sediment transport and morphological evolution. For each gauging point, data acquired during $20 \mathrm{~s}$ at an irregular rate of about 9 to $16 \mathrm{~Hz}$ were first re-sampled every $0.1 \mathrm{~s}$ to eliminate the small lag that could exist due to the measurement devices. Then, for each gauge, and for each time instant, the mean experimental value and the standard deviation were calculated. Finally, the mean standard deviation for each gauge was calculated by averaging the values of the individual time steps to obtain the range of error of the experimental data for the corresponding gauge. Following this procedure, for the ensemble of experiments, the mean observed standard deviation is between $0.006 \mathrm{~m}$ and $0.016 \mathrm{~m}$, depending on the considered gauge, with maximum values between $0.018 \mathrm{~m}$ and $0.032 \mathrm{~m}$.
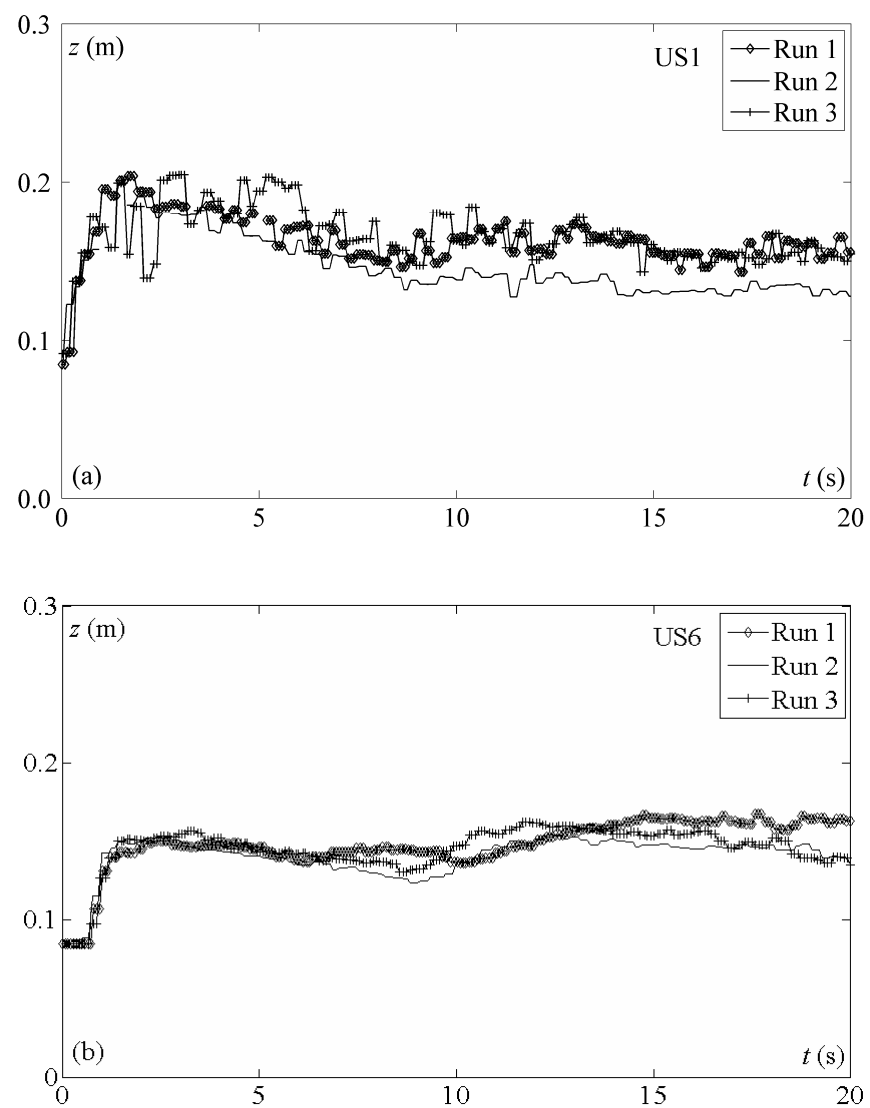

Figure 6. Repeatability of the water level measurements for three different runs of Case 1 at gauges (a) US1 and (b) US6 


\subsection{Bed elevation}

During the experiment, it was not possible to follow the scouring and deposition processes. After the passage of the dam-break wave that induced heavy morphological changes, the experiment was stopped by closing the gate after $20 \mathrm{~s}$. The bed elevation was then measured in a continuous way by means of a Delft bed profiler from $x=0.5 \mathrm{~m}$ to $x=8 \mathrm{~m}$ over the whole width of the flume, with a $\Delta y$ spacing of $0.05 \mathrm{~m}$.

As for the water level measurements, repeatability of the experiments was checked by comparing measured bed profiles issued from different experimental runs. The result is illustrated for Case 1 in Figure 7 for four different runs. It can be observed that a rather satisfactory level of repeatability could be achieved. Using the same procedure as for the measured water levels, the mean and maximum values of the standard deviation for the bed elevation measurements could be calculated as $0.008 \mathrm{~m}$ and $0.029 \mathrm{~m}$ respectively.

Combining the measured bed profiles, it was possible to reconstruct an elevation map for the final bed topography. For Case 1, such a map in perspective view is illustrated in Figure 8a. The intense scouring $(\mathrm{z}<0.085 \mathrm{~m})$ occurring immediately downstream of the failed dam can be clearly identified as well as the deposition area with a typical shape of a tongue. This is consistent with the photograph of the bed (Figure 8b) taken at the end of the experiment, after slowly pumping out the remaining water in order not to disturb the bed.
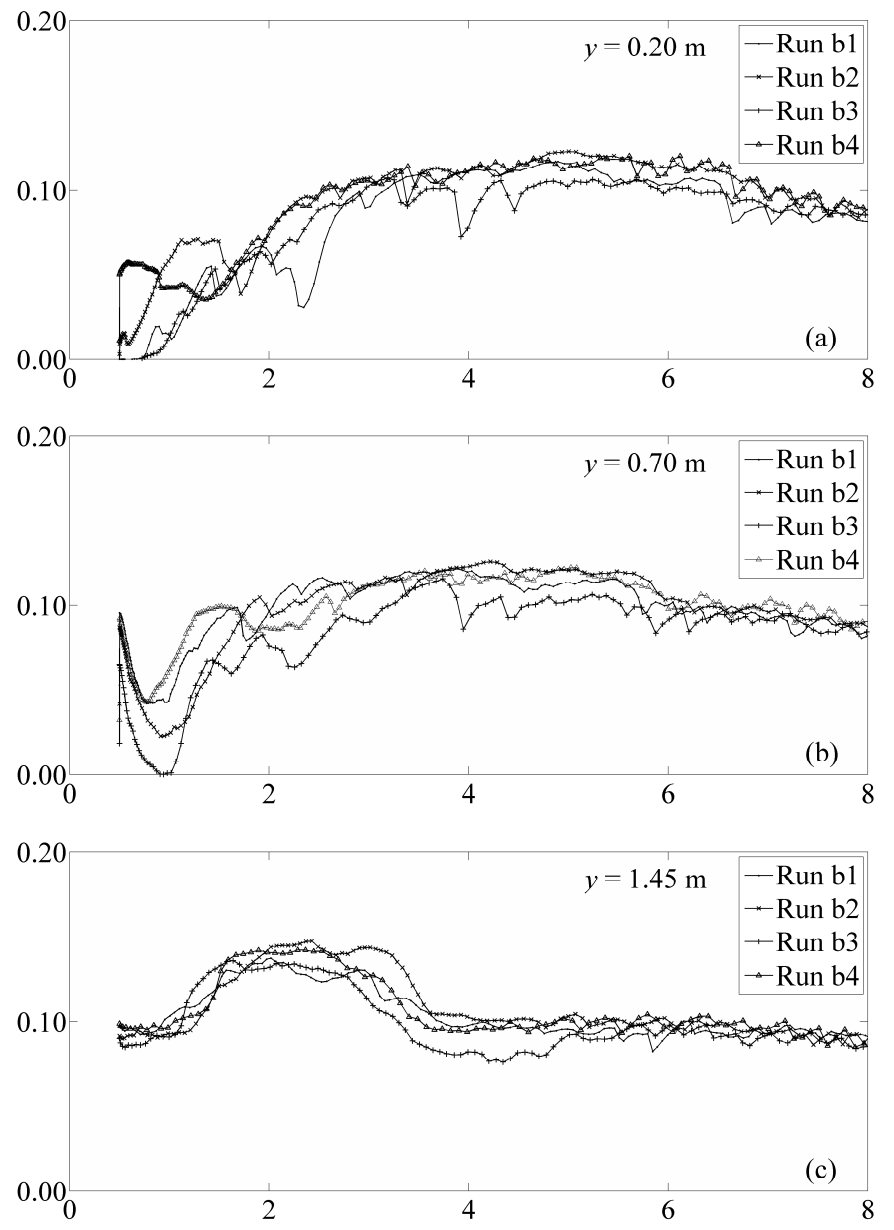
Figure 7. Repeatability of the bed elevation measurements for Case 1 from four different runs for three longitudinal profiles: (a) $y=0.20 \mathrm{~m}$, (b) $y=0.70 \mathrm{~m}$, and (c) $y=1.45 \mathrm{~m}$

The final measured bed topographies for Case 1 and Case 2 are provided in Figure 9. The key difference between Case 1 and Case 2 clearly appears here: in the latter, the bed topography shows the residual presence of antidunes that formed during the passage of the dam-break wave. After stopping the experiment, the amplitude of the bedforms decreased, but still a good trace of these remained (Figure $9 b$ ).
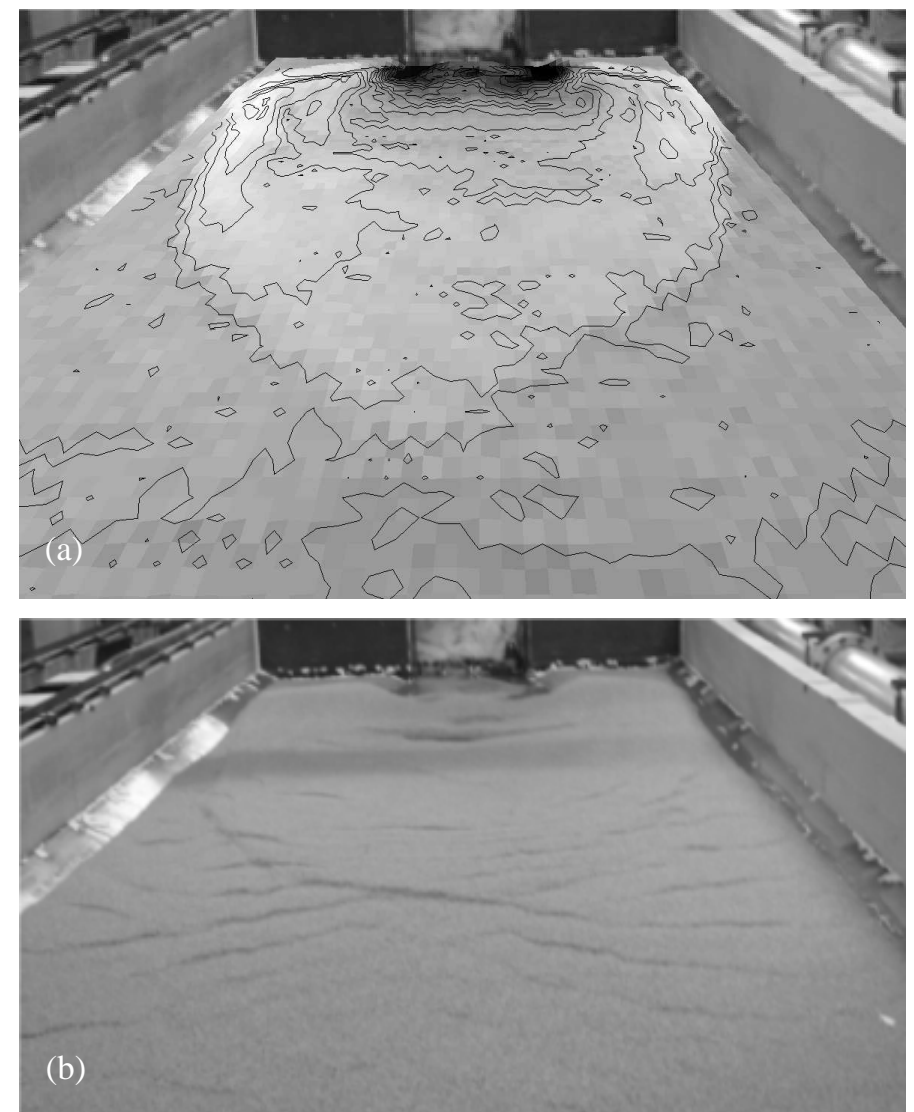

Figure 8. Final bed topography for Case 1: (a) perspective view from downstream, reconstructed from the measured bed profiles and (b) photograph taken after removing the water at the end of the experiment. 

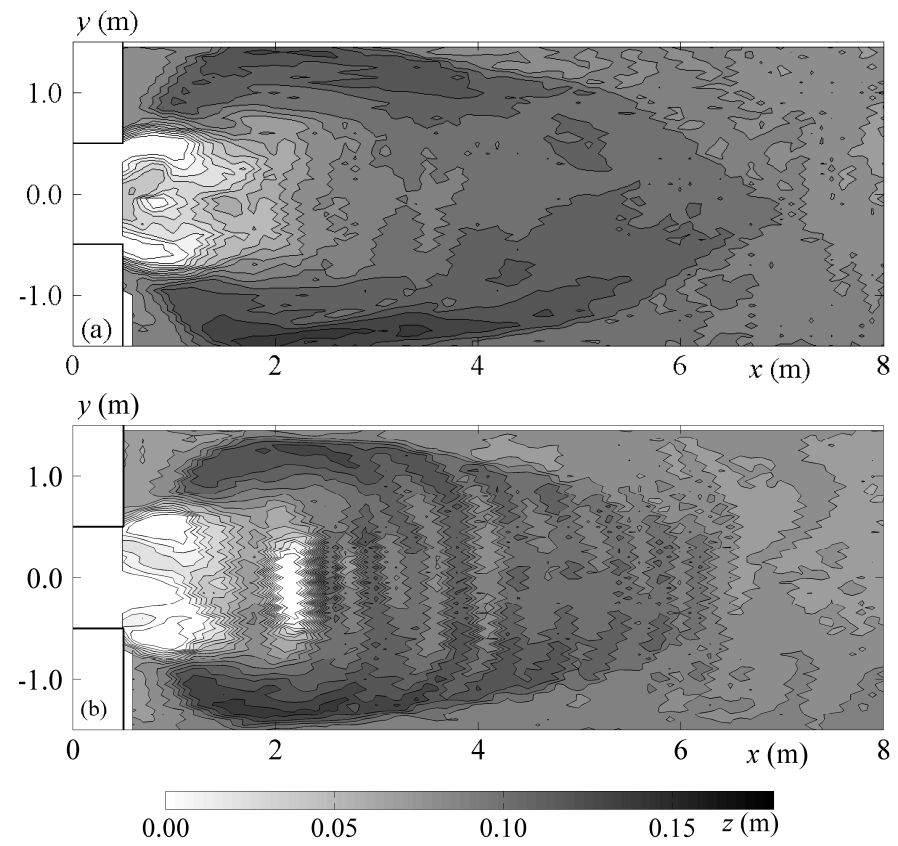

Figure 9. Final bed topography for (a) Case 1 and (b) Case 2 reconstructed from the measured bed profiles (contour lines every $0.01 \mathrm{~m}$ )

\section{Description of the simulations}

Twelve researchers or research teams (Table 3) provided simulation results for the two test cases. The simulations were conducted in a blind way, i.e. without any prior knowledge of the experimental results. The information available to the modellers consisted of:

- The dimensions of the flume (Figure 1) and a photograph of the initial sediment bed (Figure 3);

- The initial conditions for Case 1 and Case 2;

- The characteristics of the bed material: $d_{50}=1.61 \mathrm{~mm}$, specific gravity $\rho_{s} / \rho_{w}=2.63$ and porosity $\varepsilon_{0}=0.42$;

- An estimation of the Manning friction coefficients: $n=0.0165 \mathrm{~m}^{-1 / 3} \mathrm{~s}$ for the sand bed and $n=0.010 \mathrm{~m}^{-1 / 3} \mathrm{~s}$ for the fixed bed;

- A free choice for the downstream boundary condition, to be simulated either as a free outflow or a closed wall. This degree of freedom was given because it was assumed that the downstream boundary condition would not affect the bed morphological evolution during the limited duration of the experiment;

- The location of the gauges for the two considered cases.

Details about the models used by each modeller or team can be found in the references listed in Table 3. A summary of the simulation models corresponding to the received results for the benchmark tests is provided in Table 4, based on the descriptions provided by the modellers within the framework of the benchmark. 
Table 3. Sources of detailed information about each model used for the simulations

\begin{tabular}{lcl}
\hline Modellers & Name & Reference \\
\hline IST - Portugal & IST & Ferreira et al. (2009), Canelas (2010) \\
Wuhan Univ. - China & WUH & Cao et al. (2004) \\
Univ. La Coruña - Spain & COR & Cea and Vásquez-Cendón (2010), Cea et al. (2009) \\
EDF-R\&D - France & EDF & Villaret et al. (2009) \\
FLO-2D - USA & RF2D & Gonzalez-Ramirez (2010) \\
Univ. Naples - Italy & UNA & Pontillo and Greco (2010) \\
Cemagref - France & CEM & Bessenasse et al. (2004), Paquier (2009) \\
Hiroshima Univ. - Japan & HIR & Tsubaki and Fujita (2010), Shige-eda et al. (2003) \\
UCL - Belgium (1) & UCL1 & Soares-Frazão and Zech (2011) \\
UCL - Belgium (2) & UCL2 & Spinewine (2005a), Spinewine (2005b) \\
UCL - Belgium (3) & UCL3 & Swartenbroekx et al. (2010) \\
Univ. Mississipi - USA & MISS & Wu et al. (2009) \\
\hline
\end{tabular}

Regarding the flow equations, most of the modellers use the shallow-water framework complemented with a transport equation for the sediment and the associated morphological evolution. This implies the following mass conservation equation:

$$
\frac{\partial z_{w}}{\partial t}+\frac{\partial q_{x}}{\partial x}+\frac{\partial q_{y}}{\partial y}=0
$$

where $z_{w}$ is the water level, $h$ is the water depth, $q_{x}=u h$ and $q_{y}=v h$ are the unit-width total discharges (i.e. water and sediment) in the $x$ - and $y$-directions, respectively with $u$ and $v$ the depth-averaged velocity components. Considering the water phase only, this equation is sometimes simplified into

$$
\frac{\partial h}{\partial t}+\frac{\partial q_{w, x}}{\partial x}+\frac{\partial q_{w, y}}{\partial y}=0
$$

where $q_{w, x}$ and $q_{w, y}$ are the unit-width water discharges in the $x$ - and $y$-directions. The momentum conservation equations read

$$
\begin{aligned}
& \frac{\partial q_{x}}{\partial t}+\frac{\partial}{\partial x}\left(\frac{q_{x}^{2}}{h}+g \frac{h^{2}}{2}\right)+\frac{\partial}{\partial y}\left(\frac{q_{x} q_{y}}{h}\right)=g h\left(S_{o, x}-S_{f, x}\right) \\
& \frac{\partial q_{y}}{\partial t}+\frac{\partial}{\partial x}\left(\frac{q_{x} q_{y}}{h}\right)+\frac{\partial}{\partial y}\left(\frac{q_{y}^{2}}{h}+g \frac{h^{2}}{2}\right)=g h\left(S_{o, y}-S_{f, y}\right)
\end{aligned}
$$

where $g$ is the gravitational acceleration, $S_{o}$ is the bed slope and $S_{f}$ the friction slope. Again, the total unit discharges $q_{x}$ and $q_{y}$ are sometimes replaced by the water discharges only, i.e. $q_{w, x}$ and $q_{w, y}$. For the sediment, two types of continuity equations are used: either the classical Exner equation (4) or an advection equation for the sediment concentration such as the first equality of (5):

$$
\begin{gathered}
\left(1-\varepsilon_{0}\right) \frac{\partial z_{b}}{\partial t}+\frac{\partial q_{s, x}}{\partial x}+\frac{\partial q_{s, y}}{\partial y}=0 \\
\frac{\partial h C}{\partial t}+\frac{\partial q_{x} C}{\partial x}+\frac{\partial q_{y} C}{\partial y}=E-D=-\left(1-\varepsilon_{0}\right) \frac{\partial z_{b}}{\partial t}
\end{gathered}
$$

In (4), $z_{b}$ is the bed elevation, $\varepsilon_{0}$ the bed porosity, and $q_{s, x}$ and $q_{s, y}$ are the unit-width sediment transport rates in the $x$ - and $y$-directions, respectively. In (5), $C$ is the depth-averaged sediment concentration while $E$ and $D$ stand for the net erosion or deposition rate of granular material. Alternatively, introducing either (4) or (5) into (1-3) can lead to fully coupled equations (e.g. 
WUH by Cao et al. 2004). An alternative used in IST (Ferreira et al. 2009) consists in combining (5) to a total mass conservation instead of (1).

Where applicable, reference to equations (1-5) is made in Table 4. Note that models based on the same set of equations may differ by the closure equations used to describe the sediment transport rate $q_{s}$ (e.g. Meyer-Peter and Müller, Ashida-Michiue, Van Rijn) or the erosion and deposition rates $E$ and $D$. Some models consider only bedload transport while others consider a sediment concentration over the whole flow depth. Some models, such as MISS (Wu et al. 2009), considered the effects of sediment concentration and bed change in Eqs. (1)-(3), yielding the generalized shallow water (GSW) equations coupled with a non-equilibrium sediment transport model.

Alternatively, two-layer models are used by some modellers (UCL2 by Spinewine, 2005b and UCL3 by Swartenbroekx et al. 2010), to distinguish the movement of a clear water layer located above a layer consisting of a mixture of sediment and water. These models use two mass conservation equations (water and sediment) and four momentum conservation equations (water and sediment, in the $x$ and $y$-directions respectively). Finally, a two-phase model (UNA by Pontillo and Greco 2010) is also used where the solid and liquid phases are described by distinct movement equations. These latter two-layer and two-phase models explicitly consider the inertia of the mobilised sediments on the flow and have the particularity that no explicit closure equation is required for the sediment transport. Closure parameters concern either the drag coefficient (two-phase model UNA) or the interface shear stresses (two-layer model UCL2 and UCL3).

In Table 4, the acronym SW in column 'Equations' denotes the classical shallow-water equations (1-3) while the sediment transport equation is given by the equation number (4) or (5) with an indication NE for non-equilibrium transport where appropriate; in the column 'sediment closure' MPM denotes the Meyer-Peter and Müller formula for the sediment transport rate $q_{s}$; in the column 'numerical scheme' FV stands for finite volumes, FE for finite elements and HLL for the Harten-Lax-Van Leer flux calculation scheme; in the column 'downstream boundary condition' (DBC), W refers to wall and $\mathrm{O}$ to open condition. 
Table 4. Summary of simulation models

\begin{tabular}{|c|c|c|c|c|c|c|}
\hline Modellers & Name & Equations & Sediment Clc & Num. Sch. & Mesh & $\mathrm{DBC}$ \\
\hline $\begin{array}{l}\text { IST - Portugal } \\
\text { Canelas and Ferreira } \\
(2010)\end{array}$ & IST & $\begin{array}{l}\text { Inertia } \\
\text { coupled } \\
\mathrm{SW}+(5)+\mathrm{NE}\end{array}$ & $\begin{array}{l}\text { Ferreira et al. } \\
(2009) \text { sheet flow } \\
\text { formulae }\end{array}$ & $\begin{array}{l}\text { FV } \\
\text { Flux vector } \\
\text { splitting }\end{array}$ & $\begin{array}{l}\text { Triangles } \\
0.01 \mathrm{~m}\end{array}$ & $\mathrm{~W}$ \\
\hline $\begin{array}{l}\text { Wuhan Univ. - China } \\
\text { Cao et al. (2010) }\end{array}$ & WUH & $\begin{array}{l}\text { Mixture } \\
\text { cont. and } \\
\text { momentum }\end{array}$ & $q_{s}: \mathrm{MPM}$ & $\begin{array}{l}\text { FV } \\
\text { Approx. Riem. } \\
\text { solver }\end{array}$ & $\begin{array}{l}\text { Square } \\
0.02 \mathrm{~m}\end{array}$ & $\mathrm{O}$ \\
\hline $\begin{array}{l}\text { Univ. La Coruña - Spain } \\
\text { Cea et al. (2010) }\end{array}$ & $\begin{array}{l}\text { COR2 } \\
\text { COR3 }\end{array}$ & $\begin{array}{l}\mathrm{SW}+(4) \\
+\mathrm{NE}\end{array}$ & $\begin{array}{l}\tau_{\mathrm{c}}{ }^{*}: \text { Parker } \\
q_{s}: \text { MPM } \\
\tau_{\mathrm{c}}{ }^{*}: \text { Parker } \\
q_{s}: \text { Van Rijn } \\
\tau_{\mathrm{c}}: \text { Shields } \\
q_{s}: \text { Van Rijn }\end{array}$ & $\begin{array}{l}\text { FV } \\
\text { Roe }\end{array}$ & $\begin{array}{l}\text { Rectangles } \\
0.06 \mathrm{~m}\end{array}$ & $\mathrm{C}$ \\
\hline $\begin{array}{l}\text { EDF - France } \\
\text { Die Moran et al. (2010) }\end{array}$ & $\begin{array}{l}\text { EDF1 } \\
\text { EDF2 }\end{array}$ & $\mathrm{SW}+(4)$ & MPM & $\begin{array}{l}\text { FE implicit for } \\
\text { flow } \\
\text { FV for sediment } \\
\text { transport }\end{array}$ & $\begin{array}{l}\text { Triangles } \\
0.20 \mathrm{~m} \\
\text { Triangles } \\
0.10 \mathrm{~m}\end{array}$ & $\mathrm{O}$ \\
\hline $\begin{array}{l}\text { FLO-2D - USA } \\
\text { Gonzalez-Ramirez } \\
(2010)\end{array}$ & $\begin{array}{l}\text { RF2D2 } \\
\text { RF2D3 }\end{array}$ & $\mathrm{SW}+(4)$ & $\begin{array}{l}q_{s}: \mathrm{MPM} \\
q_{s}: \text { Yang }\end{array}$ & $\begin{array}{l}\text { FE } \\
\text { Galerkin } \\
\text { weighted } \\
\text { residual } \\
\text { method }\end{array}$ & $\begin{array}{l}\text { Triangles } \\
0.06 \mathrm{~m}\end{array}$ & $\mathrm{O}$ \\
\hline $\begin{array}{l}\text { Cemagref - France } \\
\text { Paquier and Le Coz } \\
(2010)\end{array}$ & $\begin{array}{l}\text { CEM2 } \\
\text { CEM3 }\end{array}$ & $\mathrm{SW}+(5)$ & $\begin{array}{l}\tau_{\mathrm{c}}^{*} 0.047, \operatorname{lag} 1 \mathrm{~m} \\
q_{s}: \mathrm{MPM} \\
\tau_{\mathrm{c}}^{*} 0.047, \operatorname{lag} 0.1 \mathrm{~m} \\
q_{s}: \mathrm{MPM} \\
\tau_{\mathrm{c}}^{*} 0.15, \operatorname{lag} 1 \mathrm{~m} \\
q_{s}: \mathrm{MPM}\end{array}$ & $\begin{array}{l}\text { FV } \\
\text { Roe } \\
2^{\text {nd }} \text { order } \\
\text { MUSCL }\end{array}$ & $\begin{array}{l}\text { Rectangles } \\
0.10 \mathrm{~m}\end{array}$ & $\begin{array}{c}\mathrm{W} / \mathrm{O} \\
\mathrm{W}\end{array}$ \\
\hline $\begin{array}{l}\text { Univ. Naples - Italy } \\
\text { Pontillo and Greco } \\
(2010)\end{array}$ & $\begin{array}{l}\text { UNA1 } \\
\text { UNA2 }\end{array}$ & $\begin{array}{l}\text { SW } \\
\text { 2-phase } \\
\text { NE }\end{array}$ & $\begin{array}{l}\text { Drag } C_{d}=0.30 \\
\text { Drag } C_{d}=0.05\end{array}$ & $\begin{array}{l}\mathrm{FV} \\
\text { Predictor } \\
\text {-corrector }\end{array}$ & $\begin{array}{l}\text { Rectangles } \\
0.10 \mathrm{~m}\end{array}$ & $\mathrm{O}$ \\
\hline $\begin{array}{l}\text { UCL - Belgium } \\
\text { Soares-Frazão (2010) }\end{array}$ & UCL1 & $\mathrm{SW}+(4)$ & $q_{s}: \mathrm{MPM}$ & $\begin{array}{l}\mathrm{FV} \\
\text { HLL }\end{array}$ & $\begin{array}{l}\text { Triangles } \\
0.05 \mathrm{~m}\end{array}$ & $\mathrm{~W}$ \\
\hline $\begin{array}{l}\text { UCL - Belgium } \\
\text { Spinewine (2010) }\end{array}$ & UCL2 & 2-layer & Bed shear stress & $\begin{array}{l}\mathrm{FV} \\
\text { HLL }\end{array}$ & $\begin{array}{l}\text { Rectangles } \\
0.02 \mathrm{~m}\end{array}$ & $\mathrm{~W}$ \\
\hline $\begin{array}{l}\text { UCL - Belgium } \\
\text { Swartenbroekx (2010) }\end{array}$ & UCL3 & 2-layer & Bed shear stress & $\begin{array}{l}\text { FV } \\
\text { HLL }\end{array}$ & $\begin{array}{l}\text { Triangles } \\
0.05 \mathrm{~m}\end{array}$ & $\mathrm{~W}$ \\
\hline $\begin{array}{l}\text { Hiroshima Univ. - Japan } \\
\text { Tsubaki (2010) }\end{array}$ & HIR & $\mathrm{SW}+(4)$ & $q_{s}:$ Ashida-Michiue & $\begin{array}{l}\mathrm{FV} \\
\text { FDS }\end{array}$ & $\begin{array}{l}\text { Triangles } \\
0.05 \mathrm{~m}\end{array}$ & $\mathrm{O}$ \\
\hline $\begin{array}{l}\text { Univ. Mississippi - USA } \\
\text { Wu and Marsooli (2010) }\end{array}$ & MISS & $\begin{array}{l}\mathrm{GSW}+(5)+ \\
\mathrm{NE}\end{array}$ & $q_{s}: \mathrm{Wu}$, total load & $\begin{array}{l}\text { FV } \\
\text { HLL }\end{array}$ & $\begin{array}{l}\text { Rectangles } \\
0.025 \mathrm{~m}\end{array}$ & $\mathrm{O}$ \\
\hline
\end{tabular}

As for numerical models, most of the participants used finite-volume schemes. Only EDF and RF2D used finite-elements. The meshes are either unstructured triangular, or square and rectangular structured grids. Different levels of refinement are considered, the typical mesh dimension (edge length) ranging from $0.2 \mathrm{~m}$ to $0.01 \mathrm{~m}$ in the area of interest immediately downstream from the dam.

Finally, for the downstream boundary condition (DBC), as prescribed, either an open condition $(\mathrm{O})$ or a closed wall $(\mathrm{W})$ was used. It must be recalled that the experiment was 
stopped after $20 \mathrm{~s}$ by closing the gate since no more significant bed evolution occurred. For Case 1, this end time is such that the downstream boundary condition does not affect the bed morphological evolution in the area of interest, as the back wave issued from the water reflection against the downstream wall has not enough time to reach the concerned area. This was checked numerically by several modellers. For Case 2, the influence of the downstream boundary condition arises earlier: in the case of a closed wall condition, the back wave reaches the area of interest before the end of the experiment. As checked by several modellers, the consequences are significant for the water level but rather limited for the bed elevation.

\section{Overview of the results}

Despite the difficulty of the exercise, all models provided valuable results giving an idea of the ability of current models to simulate such a fast transient flow with significant morphological evolution. In some cases, the water level is predicted with a good accuracy while the bed evolution is underestimated, in other cases the bed evolution is better predicted than the water level. Rather than ranking the numerical results according to the degree of verisimilitude with the experimental data, the most significant results are analysed with the aim of highlighting the key issues to be further investigated in the field of dam-break flows over mobile beds.

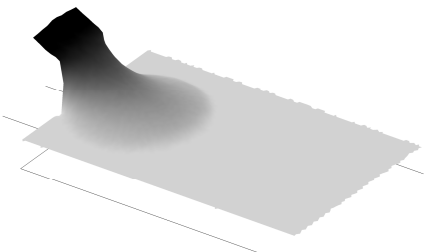

(a)

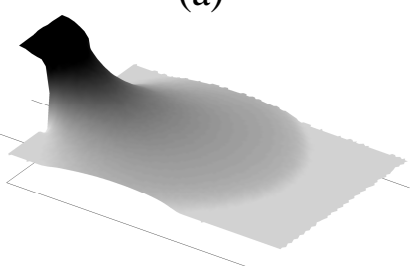

(b)

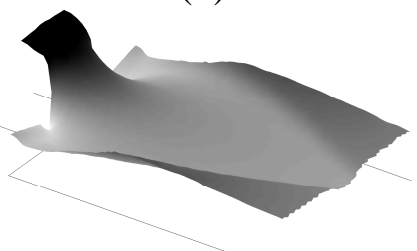

(c)

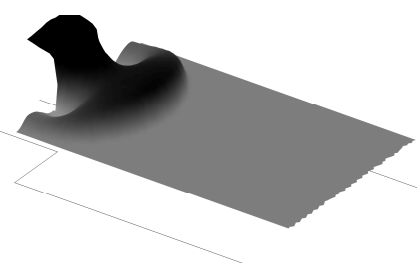

(d)

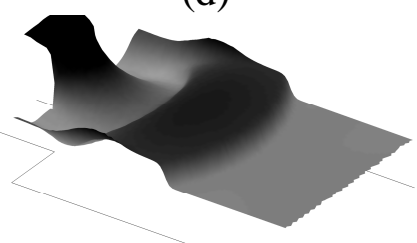

(e)

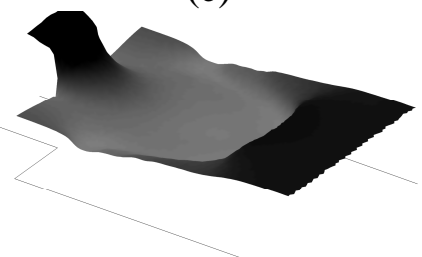

(f)

Figure 10. Computed water level from UCL1 at $t=1 \mathrm{~s}, t=2 \mathrm{~s}, t=5 \mathrm{~s}$ for Case 1 (a-b-c) and Case 2 (d-e-f)

\subsection{Water-level prediction}

Case 1 can be considered to be similar to a dam-break flow over initially dry bed, while Case 2 would correspond to a flow over wet bed. The first instants of the flow are illustrated for both test cases in Figure 10 using numerical results from the UCL1 model. The simulation 
qualitatively illustrates the observed flow features: the two-dimensional wave expansion immediately downstream of the gate and the reflections against the lateral walls of the flume. Figure 11 shows comparisons between selected numerical results and measured water levels. For the clarity of the figure, the experimental data were re-sampled every second. From the comparisons between measured and computed water levels in Figure 11, it can be observed that the results are generally better for Case 2 than Case 1 . This is particularly significant for the water level at gauge US1 (Figures 11a and 11c), located close to the corner of the dam abutment, i.e. in the area where two-dimensional spreading effects of the wave are the most important. For Case 2, the formation of the bore upon arrival of the fast dam-beak wave in the downstream layer of water at rest can be clearly identified in the measurements, and is reasonably well reproduced by the numerical models (Figure 11d).
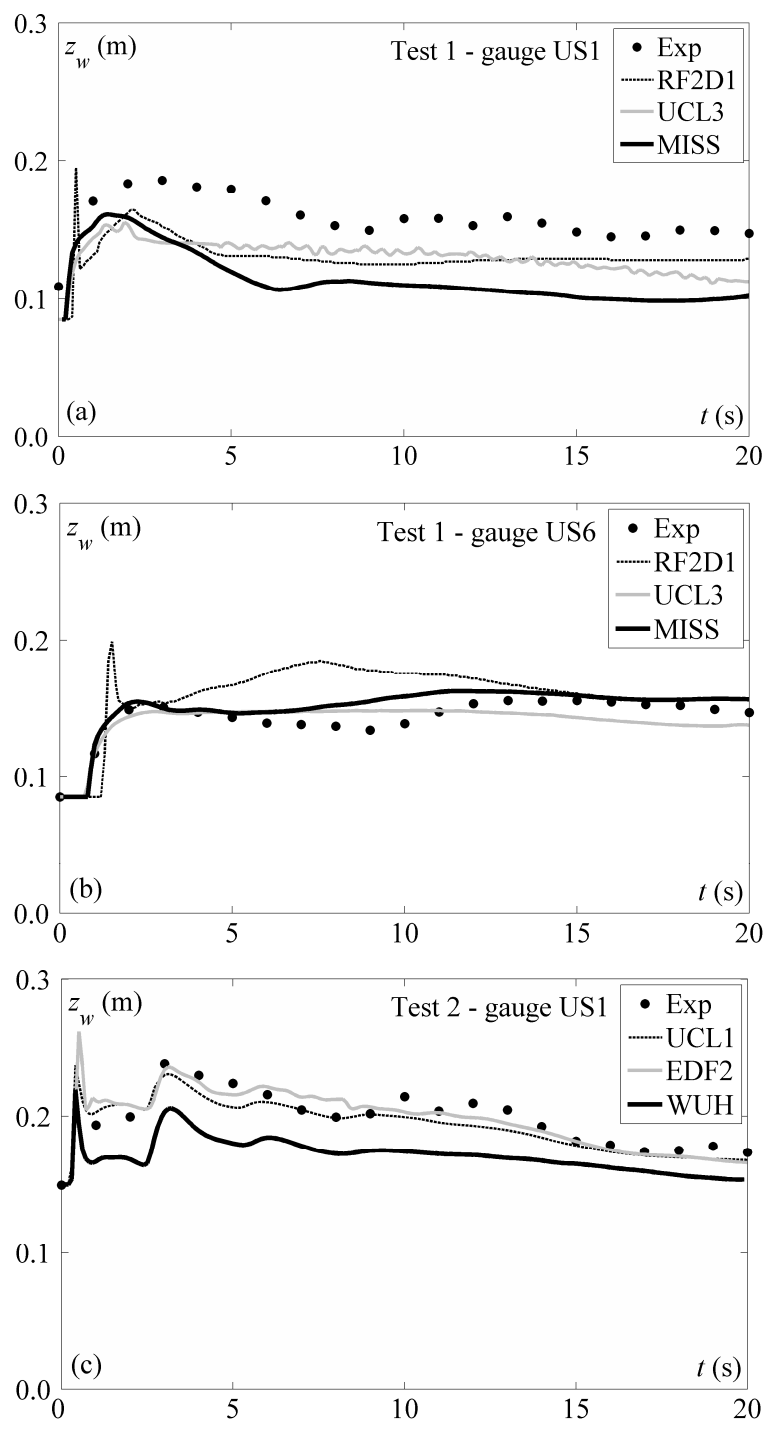


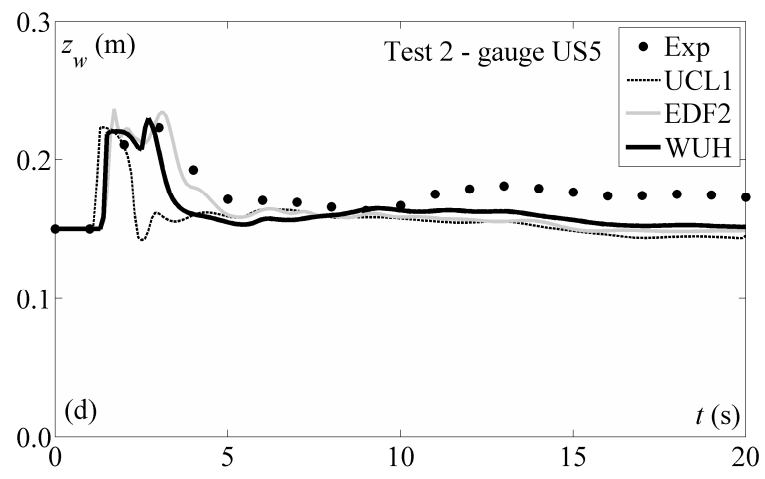

Figure 11. Measured and some computed water levels for (a) Case 1-US1, (b) Case 1-US6, (c) Case 2-US1 and (d) Case 2-US5

\subsection{Bed-level prediction}

The final bed topography was the key element of comparison in the benchmark tests. While all models were able to predict the occurrence of a scouring immediately downstream of the gate and the shape of the deposition area, the amplitude of these phenomena was usually underestimated (for example Case 1 in Figure 12). This underestimation appears to be more significant for coarse-mesh results (Figure 12c-d) than for fine-mesh results (Figure 12a-b).

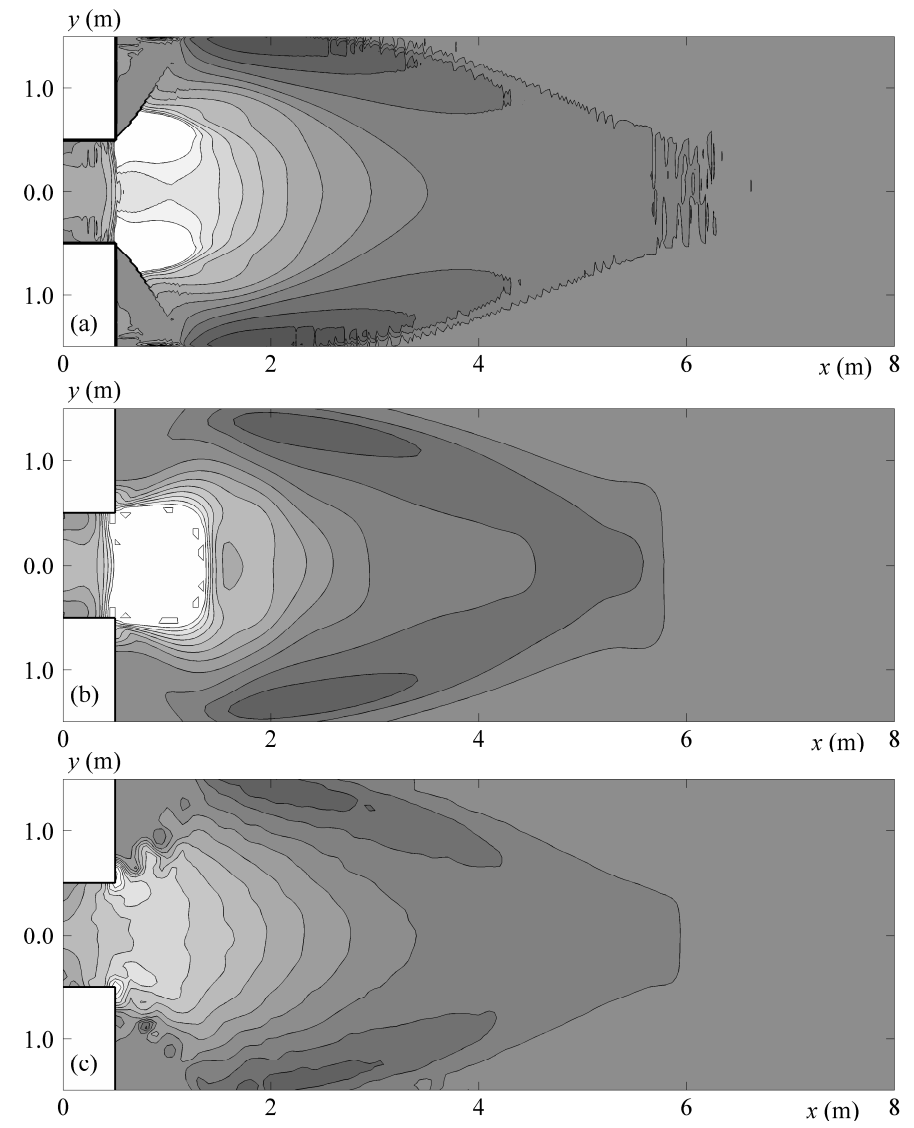




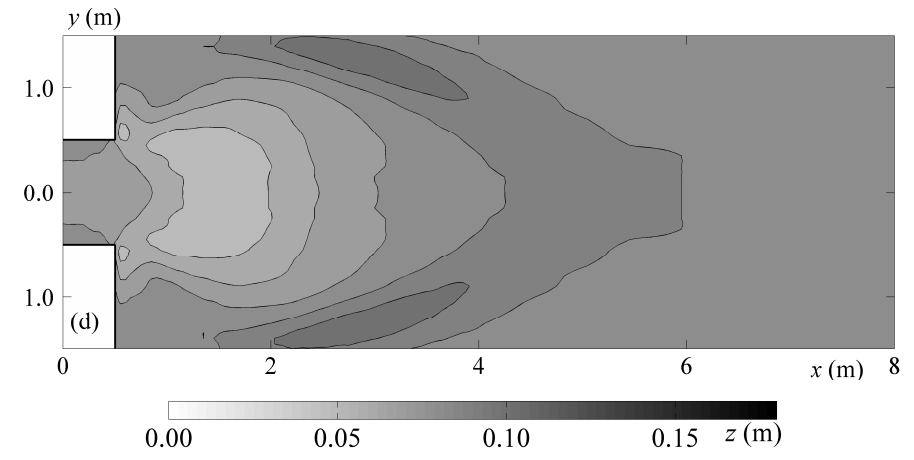

Figure 12. Computed bed topography for Case 1: Fine-mesh results by (a) WUH and (b) MISS. Coarse-mesh results by (c) EDF2 and (d) UNA2

\subsection{Influence of the choice of the sediment transport formula}

Some modellers investigated the influence of the sediment transport formula and of some parameters in the closure equations. Results are illustrated in Figure 13 for Case 1. In this figure, the experimental profiles issued from the four experimental series of Figure 7 are plotted as light lines, to provide a visual indication of the range of variability of the results. The computed results are plotted as a thick black line. Quite logically, the critical shear stress $\tau_{c}{ }^{*}$ (threshold of sediment mobilisation) appears to be a key parameter for the transport of bed material. Particularly, the formula by Parker leads to more intense transport than the classical value derived from the Shields diagram.

(a)
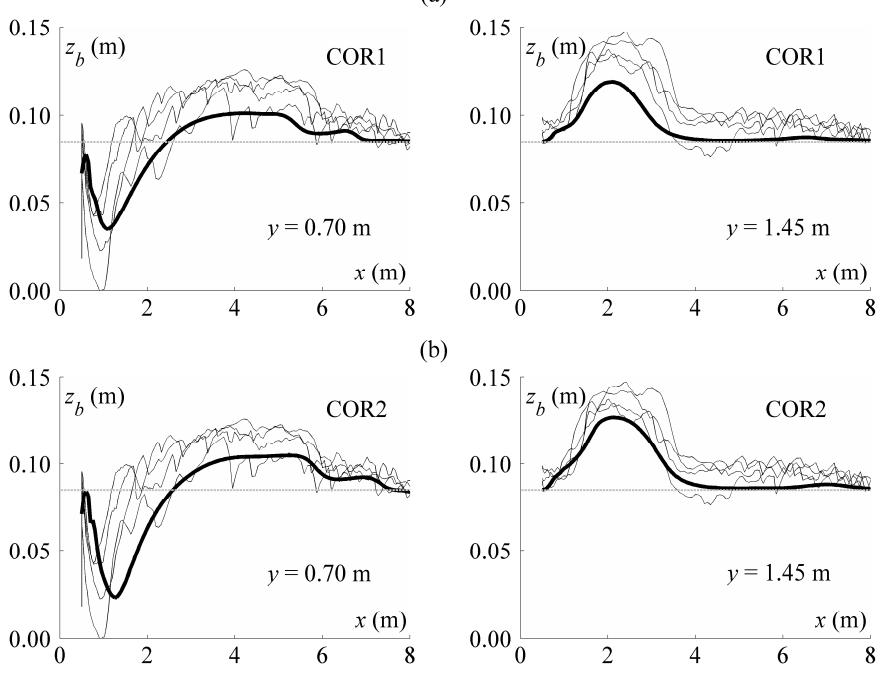

(b)
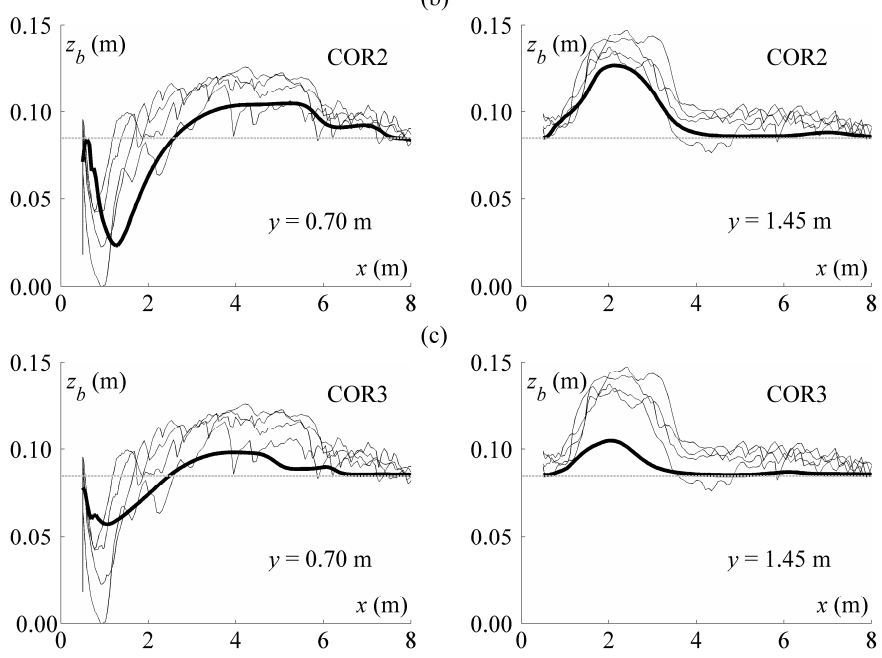

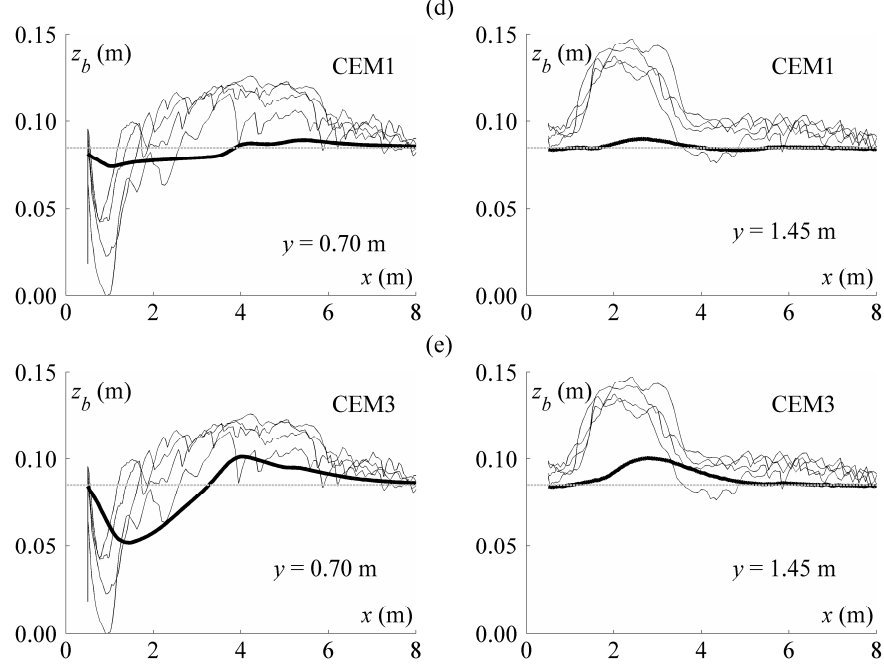

Figure 13. Influence of the sediment transport formula and closure parameters analysed from the results by Cea et al. (a-b-c) and Paquier and Le Coz (d-e): (a) $\tau_{c}{ }^{*}$ by Parker and $q_{s}$ by Meyer-Peter and Müller, (b) $\tau_{c}{ }^{*}$ by Parker and $q_{s}$ by Van Rijn, (c) $\tau_{c}{ }^{*}$ by Shields and $q_{s}$ by Van Rijn, (d) $\tau_{c}{ }^{*}=0.047$

(Shields) and $q_{s}$ by Meyer-Peter and Müller, (e) $\tau_{c}{ }^{*}=0.15$ and $q_{s}$ by Meyer-Peter and Müller.

The light grey lines refer to experimental results; the thicker line to the numerical results. 


\subsection{Bed forms}

In Case 2, due to the initial downstream water layer over the sediment bed, the wave propagation is such that antidune-type bed forms appear (Figure 9). It is interesting to note that some models run on very fine meshes were able to reproduce qualitatively the formation of these bed forms, as illustrated for UCL2 at time $t=15 \mathrm{~s}$ in Figure 14.

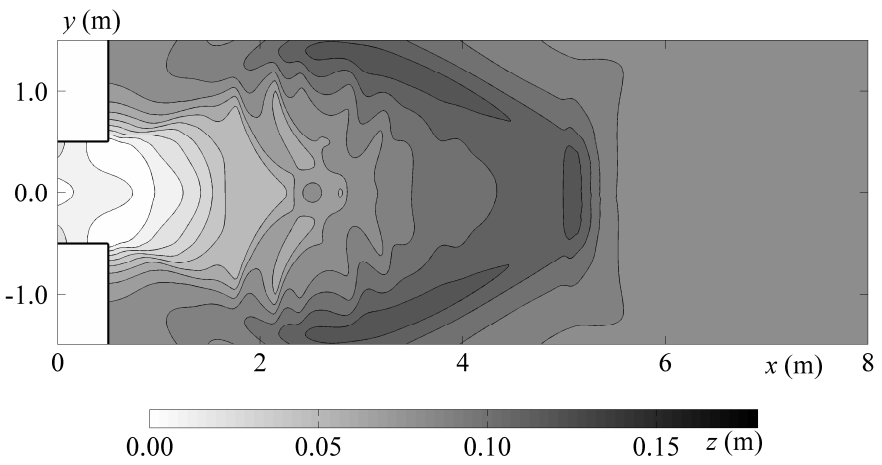

Figure 14. Bed topography at $t=15 \mathrm{~s}$ for Case 2 from UCL2 with some indication of bed forms

\subsection{Some observed numerical difficulties}

Numerical instabilities were observed for some sets of results, for various reasons, e.g. the choice of the value for the drag parameter (UNA model), the level of coupling between hydrodynamic and morphological equations, the limitation scheme in case of higher-order methods. It is however interesting to note that the computed water level was usually much more affected than the computed bed elevation. In particular, the results HIR for Case 1 illustrated in Figure 15 show a surprisingly good agreement with the final measured bed topography in terms of scour and deposition amplitude, while the water level presents important oscillations, indicating some not yet resolved instabilities.

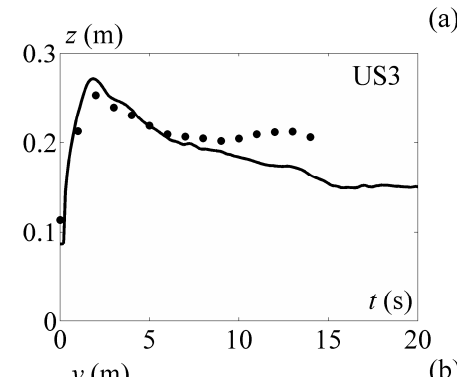

(a)
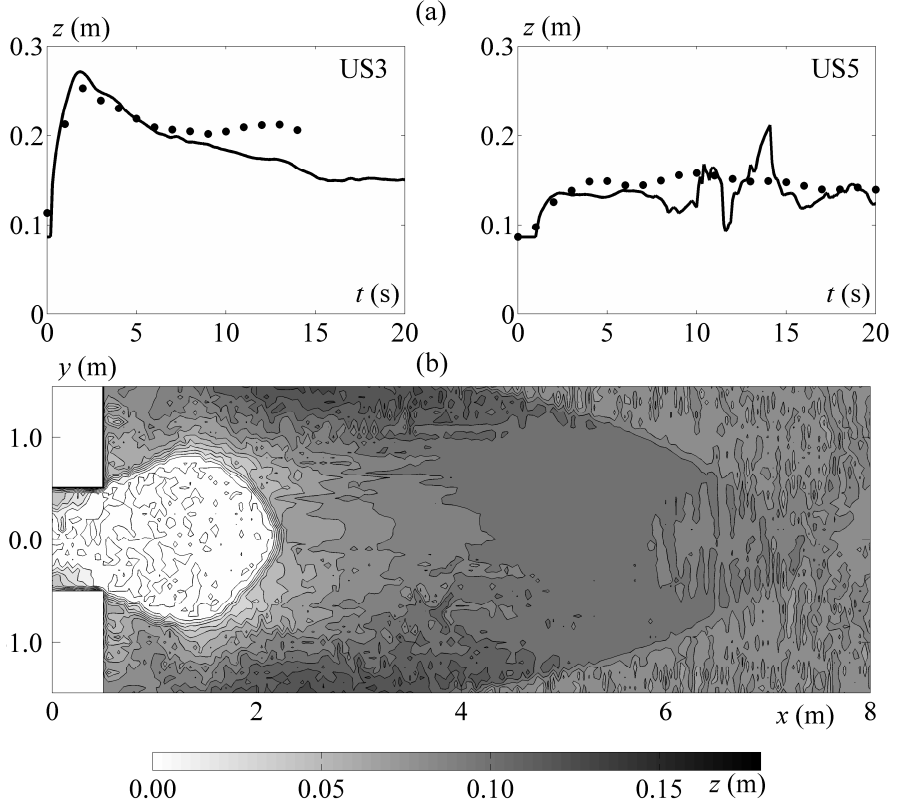
Figure 15. Computed results for Case 1 (HIR):

(a) water level at gauges US3 and US5 (The dots refer to experimental results; the black lines to the numerical results) and (b) final topography

Irregularities that however do not preclude a stable solution were observed in the results from IST for Case 2, illustrated in Figure 16, where an indication of possible bedforms can also be observed.

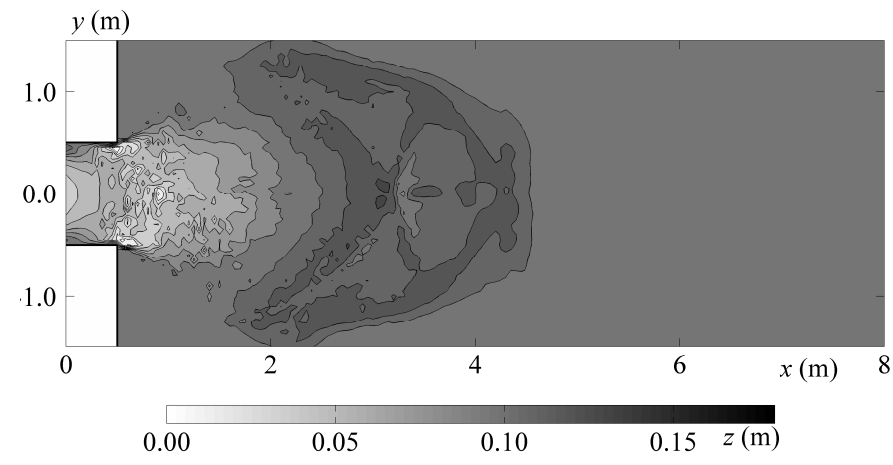

Figure 16. Final bed topography for Case 2 from IST

\section{Conclusions}

A detailed experimental data set regarding two cases of two-dimensional dam-break flows over mobile beds was presented, together with the results of a benchmarking exercise consisting of blind simulation of these two test cases. The success of this benchmark that brought together twelve teams of modellers from eight different countries all over the world constitute in itself an indication of (i) the interest for modelling issues involving 2D sediment transport and (ii) the need for such detailed data sets. As the simulations were run without any prior knowledge from the modellers of the experimental measurements, the results can be considered as an overview of the capabilities of some current models, run without any calibration. This of course is incomplete comparison as not all the possible modelling options were represented. However it gives a good idea of what models are able to do, and what should be improved or further investigated.

First of all, all models were able to produce plausible results, although some could not avoid the presence of numerical instabilities. The water free-surface was reasonably well reproduced, with the two-dimensional wave expansion immediately downstream of the gate and the reflections against the lateral walls of the flume. Most of the discrepancies may be attributed to the very rough calibration of the friction coefficient, as the only available information consisted of an indicative Manning's $n$ value and the $d_{50}$ of the bed material.

Regarding the bed evolution, all models predicted scour at the dam location and deposition further downstream. However, significant discrepancies were observed in the shape of the deposition area and in the amplitude of scouring and deposition. The prediction of the bed evolution seems less accurate than the water level modelling.

Quite logically, it could be observed that mesh refinement allowed a significant improvement of the results, with some limitations however in the mesh size: very fine meshes with sizes of $0.025 \mathrm{~m}$ or less were not always better than medium-sized meshes of about $0.05 \mathrm{~m}$.

Concerning the sediment transport closure equations, nothing clear could be concluded at this stage. The value or formula adopted for the critical shear stress determining the initiation of movement appears as a key issue, but no "best value" could be deduced from the available results. Similar conclusions arise for the transport rate formula. 
As regards the governing equations themselves, no clear difference can be made between classical or generalized shallow-water approaches, two-layer or two-phase models. A conclusion that could be drawn is that the present measurements do not allow identifying any significant inertia effects that could induce more differences between the models. This is mainly due to the fact that although rapid morphological changes occur with intense sediment transport, only bedload occurring in a thin sheet-flow layer is observed.

Finally, it can be concluded that this modelling exercise highlights the need for further research in the field of fast transient flows involving intense sediment transport and morphological changes, as no complete agreement exists about the governing mechanisms. In particular the link between the solid transport and the depth-averaged velocity, in magnitude and in direction, is probably a key issue of $2 \mathrm{D}$ morphological modelling. The closure relations describing this link between hydrodynamic flow and sediment response are not universally established and often too demanding in calibration of multiple parameters. Also, the adequacy of the Manning approach for friction losses in such fast transient cases would certainly be a question to be addressed in future work. There is still a long way to model in a simplified but accurate way a complex morphological evolution.

\section{Acknowledgements}

The authors wish to acknowledge the support of the technicians from LEMSC and the UCL Msc students who helped in performing the experiments and measurements leading to this benchmark tests: Pierre Henriet, David Hick, Alexandre Rouvez and Thibaut Mahieu. The authors also acknowledge the financial support from NSF (USA) through the PIRE project (grant $\mathrm{n}^{\circ}$ OISE 0730246), the financial support from FRS-FNRS (Belgium) and the support from the IAHR Fluvial Hydraulics Committee for the creation of the "Working group for dam-break flows over mobile beds".

\section{List of authors, in alphabetic order}

Ricardo Canelas, Instituto Superior Técnico, Portugal

Zhixian Cao, Wuhan University, China

Luis Cea, Universidad da Coruña, Spain

Hanif Chaudhry, University of South Carolina, USA

Andres Die Moran, EDF, France

Kamal El Kadi, EDF, France

Rui Ferreira, Instituto Superior Técnico, Portugal

Ignacio Fraga Cadórniga, Universidad da Coruña, Spain

Noemi Gonzalez-Ramirez, RiverFlo-2D, USA

Massimo Greco, University of Naples Federico II, Italy

Wei Huang, Wuhan University, China

Jasim Imran, University of South Carolina, USA

Jérôme Le Coz, Cemagref, France

Reza Marsooli, University of Mississippi, USA

André Paquier, Cemagref, France

Gareth Pender, Heriot-Watt University, UK.

Marianeve Pontillo, University of Naples Federico II, Italy

Jeronimo Puertas, Universidad da Coruña, Spain

Sandra Soares-Frazão, Université catholique de Louvain, Belgium 
Benoit Spinewine, Université catholique de Louvain, Belgium

Catherine Swartenbroekx, Université catholique de Louvain, Belgium

Ryota Tsubaki, Hiroshima University, Japan

Catherine Villaret, EDF, France

Weiming Wu, University of Mississippi, USA

Zhiyuan Yue, Yangtze River Waterway Research Institute, China

Yves Zech, Université catholique de Louvain, Belgium

\section{References}

Bessenasse M., Kettab A., Paquier A. (2004). Modélisation bidimensionnelle du dépôt de sédiments dans un barrage en Algérie. La Houille blanche 1, 31-36.

Brooks G.R., Lawrence D.E. (1999). The Drainage of the Lake Ha! Ha! Reservoir and Downstream Geomorphic Impacts Along Ha! Ha! River, Saguenay Area, Quebec, Canada. Geomorphology 28, 141-168.

Canelas R. (2010). 2D Mathematical Modeling of Discontinuous Shallow Sediment-laden Flows. Master Thesis. Instituto Superior Técnico - Universidade Técnica de Lisboa, Lisboa.

Canelas R., Ferreira R. (2010). PIRE Workshop on Dam-break Flows - November 2010 - Description of Computational Model SF2D. NSF-PIRE 2010 workshop "Dam-break flow on mobile bed", private communication available at http://www.uclouvain.be/373040.html, 7 pages.

Cao Z, Huang W, Yue Z, Pender G. (2010). Coupled 2D mathematical modeling of dam break flow over erodible bed - UCL test case. NSF-PIRE 2010 workshop "Dam-break flow on mobile bed", private communication available at http://www.uclouvain.be/373040.html, 10 pages.

Capart H. (2000). Dam-break induced geomorphic flows and the transition from solid- to fluid-like behaviour across evolving interfaces. PhD thesis. UCL, Belgium.

Capart H., Spinewine B., Young D.L., Zech Y., Brooks G.R., Leclerc M., Secretan Y. (2007). The 1996 Lake Ha! Ha! breakout flood, Québec: Test data for geomorphic flood routing methods. $J$. Hydraulic Res. 45 (Extra Issue), 97-109.

Cea, L., Puertas, J., Fraga, I., Trell, R., Balairon, L. (2009). Numerical modelling of the effects of river discharge regulation on the morphology and sediment transport dynamics in a shallow estuary. 33rd IAHR Congress, Vancouver, Canada, 9-14 August 2009, 3704-3711 (CD-ROM).

Cea, L., Vázquez-Cendón, M.E. (2010). Unstructured finite volume discretisation of two-dimensional depth averaged shallow water equations with porosity. Int. J. Num. Meth. Fluids 63 (8), 903-930.

Cea L., Fraga I., Puertas J. (2010). PIRE workshop on dam-break flows - November 2010 - Proposed benchmark: Two-dimensional dam-break flow on movable bed. NSF-PIRE 2010 workshop "Dambreak flow on mobile bed", private communication available at http://www.uclouvain.be/373040.html, 9 pages.

Die Moran A., El Kadi Abderrezzak K., Villaret C. (2010). NSF PIRE benchmarking workshop: Twodimensional depth-averaged dam-break flow on mobile bed. Results submission. NSF-PIRE 2010 workshop "Dam-break flow on mobile bed", private communication available at http://www.uclouvain.be/373040.html, 1 page.

Gonzalez-Ramirez N. (2010). Description of the benchmark simulation: two-dimensional dam-break flow on movable bed. NSF-PIRE 2010 workshop "Dam-break flow on mobile bed", private communication available at http://www.uclouvain.be/373040.html, 13 pages.

Hervouet J. M., Petitjean, A. (1999). Malpasset dam break revisited with two-dimensional computations. J. Hydraulic Res. 37 (6), 777-788.

Nguyen D.K. Shi Y-E, Wang S.S.Y., Nguyen T.H. (2006). 2D Shallow-Water Model Using Unstructured Finite-Volumes Methods. J.Hydraulic Eng. 132 (3), 258-269. 
Paquier, A. (2009). Logiciel Rubar 20. Notice d'emploi. Cemagref, Unité de Recherche Hydrologie Hydraulique, Lyon, France, 60 pages.

Paquier A., Le Coz J. (2010). PIRE workshop on dam-break flows. Benchmark: two-dimensional dam-break flow on movable bed. Description of calculations performed by Cemagref. NSF-PIRE 2010 workshop "Dam-break flow on mobile bed", private communication available at http://www.uclouvain.be/373040.html, 3 pages.

Pontillo M., Greco M. (2010). The PIRE Benchmark. NSF-PIRE 2010 workshop "Dam-break flow on mobile bed", private communication available at http://www.uclouvain.be/373040.html, 9 pages.

Roger, S., Dewals, J., Erpicum, S., Schwanenberg, D., Schüttrumpf, H., Köngeter, J., Pirotton, M., (2009). Experimental and numerical investigations of dike-break induced flows. J. Hydraulic Res. 47, 349-459.

Shige-eda, M., Akiyama, J., Yamasaki, T. (2003). Numerical model based on FDS technique for 1D bed variation. Annual Journal of Hydraulic Engineering, JSCE 47, 667-672 (in Japanese).

Soares Frazão S., Zech Y. (2007). Experimental study of dam-break flow against an isolated obstacle. J. Hydraulic Res. 45 (Extra Issue), 27-36.

Soares-Frazão S. (2010). Two-dimensional finite-volume model for shallow-water flow over fixed and mobile bed. Application to the UCL benchmark: "Dam-break flow over mobile bed. NSF-PIRE 2010 workshop "Dam-break flow on mobile bed", private communication available at http://www.uclouvain.be/373040.html, 4 pages.

Soares-Frazão S., Zech Y. (2011). HLLC scheme with novel wave-speed estimators appropriate for two-dimensional shallow-water flow on erodible bed. Int. J. Num. Meth. Fluids 66(8), 1019 - 1036.

Spinewine, B. (2005a). Two-Layer Flow Behaviour and the Effects of Granular Dilatancy in DamBreak Induced Sheet-Flow. PhD Thesis n०76|2005, Université catholique de Louvain, Belgium.

Spinewine, B. (2005b). Two-layer shallow water modelling of fast geomorphic flows and experimental validation on idealised laboratory dam-break waves. XXXI IAHR Congress, September 11-16, Seoul, Korea, 6477-6488.

Spinewine B. (2010). UCL-Spinewine: Two-Layer Geomorphic Shallow-Water equations. NSF-PIRE 2010 workshop "Dam-break flow on mobile bed", private communication available at http://www.uclouvain.be/373040.html, 2 pages.

Swartenbroekx C. (2010). PIRE workshop on 2D dam-break flows over erodible bed - November 2010. Brief description of a 2D two-layer model for dam-break flows. NSF-PIRE 2010 workshop "Dam-break flow on mobile bed", private communication available at http://www.uclouvain.be/373040.html, 3 pages.

Swartenbroekx C., Soares-Frazão S., Spinewine B., Guinot V., Zech Y. (2010). Hyperbolicity preserving HLL solver for two layer shallow-water equations applied to dam-break flows. Proceedings of the River Flow 2010 Conference, A. Dittrich, K. Koll, J. Aberle, P. Geisenhainer (Eds), Braunschweig, Germany, Vol. 2, 1379-1387.

Tsubaki R. (2010). Description of the simulation. NSF-PIRE 2010 workshop "Dam-break flow on mobile bed", private communication available at http://www.uclouvain.be/373040.html, 10 pages.

Tsubaki R., Fujita, I (2010). Unstructured grid generation using LiDAR data for urban flood inundation modeling. Hydrological processes 24, 1404-1420, DOI: 10.1002/hyp.7608.

Valiani A., Caleffi V., Zanni A. (2002). Case Study: Malpasset Dam-Break Simulation using a TwoDimensional Finite Volume Method. J. Hydraulic Eng. 128 (5), 460-472.

Villaret C., Hervouet J.M., Huybrechts N., Van L.A., Davies A.G. (2009). Effect of bed friction on morphodynamic modelling: Application to the central part of the Gironde estuary. $6^{\text {th }}$ Symp. on River, Coastal and Estuarine Morhodynamics (RCEM 2009), 21-25 September 2009, Santa-Fe (Argentina), 889-905.

Vischer, D.L., Hager, W.H. (1998). Dam Hydraulics. Wiley, Chichester, UK.

Wu, W., He, Z., Wang, S.S.Y. (2009). A depth-averaged 2-D model of non-cohesive dam/levee breach processes. Proc. 2009 World Environmental and Water Resources Congress, May 17-21, Kansas City, MO (on CD-ROM 
Wu W.,Marsooli R. (2010). Benchmark (Blind) Test of Wu's Depth-Averaged 2-D Model for DamBreak Flow over Movable Bed. NSF-PIRE 2010 workshop "Dam-break flow on mobile bed", private communication available at http://www.uclouvain.be/373040.html, 19 pages. 